\title{
NOM characterization and removal at six Southern African water treatment plants
}

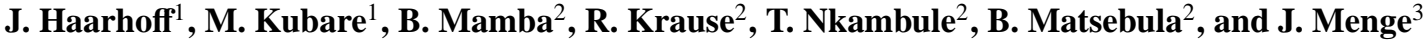 \\ ${ }^{1}$ Department of Civil Engineering Science, University of Johannesburg, \\ P.O. Box 524, Auckland Park 2006, South Africa \\ ${ }^{2}$ Department of Chemical Technology, University of Johannesburg, \\ P.O. Box 524, Auckland Park 2006, South Africa \\ ${ }^{3}$ City of Windhoek, P.O. Box 59, Windhoek, Namibia
}

Received: 17 August 2009 - Published in Drink. Water Eng. Sci. Discuss.: 10 November 2009

Revised: 8 April 2010 - Accepted: 8 April 2010 - Published: 15 April 2010

\begin{abstract}
Organic pollution is a major concern during drinking water treatment. Major challenges attributed to organic pollution include the proliferation of pathogenic micro-organisms, prevalence of toxic and physiologically disruptive organic micro-pollutants, and quality deterioration in water distribution systems. A major component of organic pollution is natural organic matter (NOM). The operational mechanisms of most unit processes are well understood. However, their interaction with NOM is still the subject of scientific research. This paper takes the form of a meta-study to capture some of the experiences with NOM monitoring and analysis at a number of Southern African Water Treatment Plants. It is written from the perspective of practical process selection, to try and coax some pointers from the available data for the design of more detailed pilot work. NOM was tracked at six water treatment plants using dissolved organic carbon (DOC) measurements. Fractionation of the DOC based on biodegradability and molecular weight distribution was done at a water treatment plant in Namibia. A third fractionation technique using ion exchange resins was used to assess the impact of ozonation on DOC. DOC measurements alone did not give much insight into NOM evolution through the treatment train. The more detailed characterization techniques showed that different unit processes preferentially remove different NOM fractions. Therefore these techniques provide better information for process design and optimisation than the DOC measurement which is routinely done during full scale operation at these water treatment plants.
\end{abstract}

\section{Introduction}

In most parts of the world there is increased concern towards the effects of organic pollution on drinking water treatment. Major challenges attributed to organic pollution include the proliferation of pathogenic micro-organisms, prevalence of toxic and physiologically disruptive organic micro-pollutants, and quality deterioration in water distribution systems (Hem and Efraimsen, 2001). However, since the number of organic compounds present in water is large, it is very difficult to monitor them individually during full scale operation. Thus, surrogate measurements are widely used. Table 1 shows selected organic pollutants that are regulated by the USEPA and in South Africa. Dissolved organic carbon (DOC) is the organic matter, measured as $C$ in $\mathrm{mg} / \mathrm{l}$, passing through a $0.45 \mu \mathrm{m}$ filter while the other parameters are classified as organic micro-pollutants. Evidently, organic micro-pollutants constitute a very small component of the organic pollution. The major fraction of the organic pollution is attributed to natural organic matter (NOM). NOM is a heterogeneous mixture of undefined structurally complex organic compounds derived from plants, animals and microorganisms and their waste and metabolic products. Therefore NOM inevitably occurs in all natural water sources. 
Table 1. Regulated organic chemicals.

\begin{tabular}{llll}
\hline Determinant & Unit & EPA max limit $(2009)^{2}$ & South African max limit $(2005)^{3}$ \\
\hline Dissolved organic carbon (DOC) & $\mathrm{mg} / 1$ & Not mentioned & 10 \\
Total Trihalomethanes (TTHMs) & $\mathrm{mg} / 1$ & 0.080 & 0.2 \\
Polychlorinated biphenyls (PCBs) & $\mathrm{mg} / 1$ & 0.0005 & Not mentioned \\
Pesticides (sum) & $\mathrm{mg} / 1$ & $0.0005^{1}$ & Not mentioned \\
$1,1,2-$ Trichloroethane & $\mathrm{mg} / 1$ & 0.005 & Not mentioned \\
Vinyl chloride & $\mathrm{mg} / 1$ & 0.002 & Not mentioned \\
Halo-acetic acids (HAA5) & $\mathrm{mg} / 1$ & 0.060 & Not mentioned \\
\hline
\end{tabular}

${ }^{1}$ Value is from European Union guidelines.

${ }^{2}$ Source: Environmental Protection Agency, USA

${ }^{3}$ Source: South African National Standard (SANS) 241 Drinking Water Specifications

NOM had been implicated as the direct cause for the formation and proliferation of some organic micro-pollutants. Chlorination of NOM can lead to the formation of trihalomethanes (THMs), and reaction with ozone can form toxic peroxide radicals, and physiologically disruptive aldehydes among other harmful by-products (Amy et al., 1988; Arruda and Fromm, 1989; Gunten et al., 2001; Westerhoff et al., 2004). Additionally, NOM had been shown to be directly responsible for several physical and bio-chemical water quality problems. NOM could be responsible for the colour, undesirable taste and odour of natural waters; is a source of nutrients for heterotrophic bacteria; promotes bacterial re-growth and deposition of particles in the distribution system (Escobar and Randall, 2000; Lehtola et al., 2001; Olivieri et al., 1984; Liua et al., 2002) which compromises water quality and increases turbidity at the consumer. Furthermore, NOM interferes with the performance of several unit processes. NOM could be responsible for high coagulant demand (Edzwald and Tobiason, 1999); rapid clogging of filters by biofilm growth on media (Haarhoff and Van Staden, 2006); rapid saturation of activated carbon beds thereby increasing the regeneration frequency; high disinfectant demand; inhibition of the impact of disinfectants; rapid decay of ozone; inhibition of precipitative processes which form the backbone of drinking water treatment; is a major membrane foulant (Lee et al., 2003) and may inhibit the removal of organic micro-pollutants by activated carbon. Given the inevitable occurrence of NOM in all natural water sources, more attention should be directed towards the systematic consideration of NOM - its structure and occurrence in raw water sources, its flow and fate during water treatment processes, and its analytical fractionation into parts that can guide engineers towards more optimal process selection and design.

Larger treatment plants in Southern Africa rely almost exclusively on surface water sources, which are often compromised due to high return flows and indirect reuse. Water temperature is high, many surface water impoundments are eutrophic and NOM concentrations are high (Swartz et al., 2004). Considering the often poor performance of wastewater treatment plants, changes in land use patterns due to rapid industrial development, increased use of chemicals in agriculture, and new settlements, good drinking water has to be produced from ever changing and compromised raw water sources. The water sector is understandably concerned about the levels of NOM in drinking water, finding legal expression as a DOC guideline limit of $5 \mathrm{mg} / \mathrm{l}$ and a maximum of $10 \mathrm{mg} / \mathrm{l}$. This forced attention to the flow and fate of NOM in treatment plants, led to a number of smaller studies at different locations in recent years.

This paper takes the form of a meta-study to capture some of the experiences with NOM monitoring and analysis at a number of Southern African Water Treatment Plants (WTPs). It is written from the perspective of practical process selection, to try and coax some pointers from the available data for the design of more detailed pilot work. The main objectives are to:

1. Demonstrate that the normal routine monitoring of DOC does not bring much insight into process performance.

2. Enumerate selected methods for fractionating the NOM and their possible relevance to different treatment processes.

3. Evaluate the performance of treatment processes by tracking the removal and transformation of NOM through different treatment trains using three different fractionation techniques.

4. Assess the practical value and relevance of the information that can be extracted from these fractionation techniques. 
Table 2. WTPs configurations.

\begin{tabular}{lllll}
\hline Plant & Pre-treatment & Conventional Treatment & Advanced Treatment & Disinfection \\
\hline Vaalkop & None & EC & $\mathrm{O}_{3}+\mathrm{GAC}$ & Chloramination \\
Vereeniging & None & $\mathrm{EC}+\mathrm{ST}$ & None & Chloramination \\
Balkfontein & None & $\mathrm{EC}+\mathrm{ST}+\mathrm{RSF}$ & $\mathrm{None}$ & Free chlorine \\
Stilfontein & None & $\mathrm{DAF}+\mathrm{ST}$ & $\mathrm{O}_{3}+\mathrm{RSF}$ & Free chlorine \\
Von Bach & None & $\mathrm{ST}+\mathrm{RSF}$ & $\mathrm{None}$ & Free chlorine \\
Goreangab & Pre-ozonation & $\mathrm{EC}+\mathrm{DAF}+\mathrm{RSF}$ & $\mathrm{O}_{3}+\mathrm{BAC}+\mathrm{GAC}+\mathrm{UF}$ & Free chlorine \\
\hline
\end{tabular}

$\mathrm{EC}=$ Enhanced Coagulation, $\mathrm{ST}=$ Settling Tank, RSF $=$ Rapid Sand Filtration, $\mathrm{DAF}=$ Dissolved Air Flotation, $\mathrm{O}_{3}=\mathrm{Ozonation}$ $\mathrm{GAC}=$ Granular Activated Carbon, $\mathrm{BAC}=$ Biological Activated Carbon, UF $=$ Ultrafiltration

\section{Tracking unfractionated NOM during full-scale treatment}

The removal and transformation of NOM during full scale treatment was tracked using DOC measurements. DOC varies with the type of water from approximately $0.5 \mathrm{mg} / \mathrm{l}$ for groundwater and seawater to over $30 \mathrm{mg} / \mathrm{l}$ for coloured water from swamps (Thurman and Malcolm, 1981). From the perspective of evaluating NOM treatment, Chen et al. (2007) grouped unit processes into four classes:

- pretreatment (includes pre-oxidation using ozone or permanganate)

- conventional (includes enhanced coagulation, dissolved air flotation, settling and rapid sand filtration)

- advanced (includes granular activated carbon, oxidation preceding biofiltration and membrane filtration)

- disinfection (includes free chlorine, chloramination, or sequential chlorination)

In this paper we present results from six water treatment plants (WTPs) in Southern Africa, namely: Vaalkop (owned and operated by Magalies Water, South Africa), Vereeniging (Rand Water, South Africa), Balkfontein (Sedibeng Water, South Africa), Stilfontein (Midvaal Water, South Africa), Von Bach (NamWater, Namibia) and Goreangab (Windhoek City Council, Namibia). The configurations of the WTPs studied are shown in Table 2 according to the classification of Chen et al. (2007). Pretreatment is only applied at Goreangab. Conventional treatment forms the core of the NOM treatment at the Vereeniging, Balkfontein and Von Bach WTPs. Advanced treatment is applied at Vaalkop where ozonation precedes granular activated carbon; Stilfontein where ozonation precedes rapid sand filtration; and Goreangab which has a comprehensive treatment scheme comprising of ozonation, biological activated carbon, granular activated carbon, and ultrafiltration as advanced treatment steps.

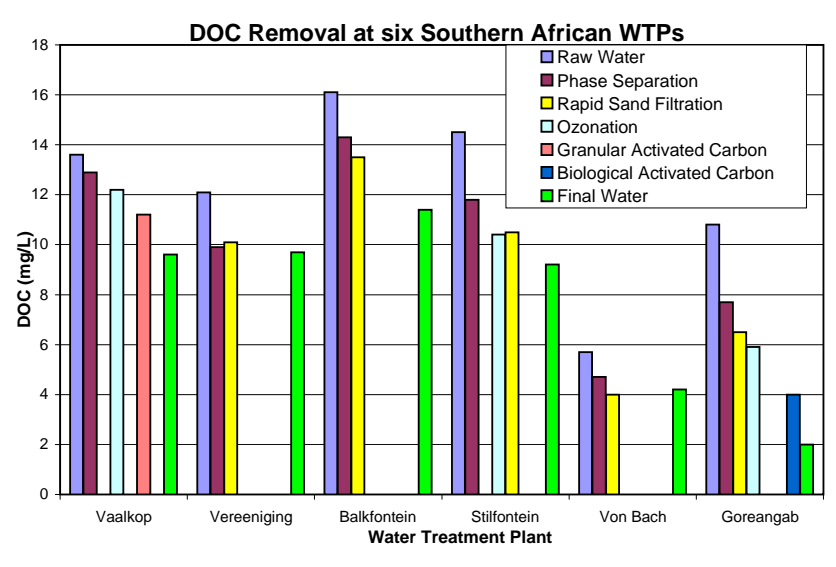

Figure 1. DOC removal for the individual unit processes at the six Water Treatment Plants.

\subsection{Experimental}

During full scale operation, DOC is only measured in the raw and final water. In order to evaluate each individual unit process, additional sampling and laboratory analyses were required to supplement the routine monitoring data. Samples were collected from the raw water, after each unit process and from the final treated water. Two litres of each sample were collected at each site, stored in the refrigerator at $4{ }^{\circ} \mathrm{C}$ and analysed within $24 \mathrm{~h}$. DOC was measured by quantifying the amount of carbon dioxide formed upon incineration of a water sample (after filtration through a $0.45 \mu \mathrm{m}$ membrane filter) in a Total Organic Carbon (TOC) analyzer. This sampling and analysis programme formed part of a postgraduate project at the Department of Chemical Technology at the University of Johannesburg and is fully documented elsewhere (Matsebula, 2009). 
Table 3. DOC removal per unit process at the six WTPs (total removal not equal to sum of processes due to not all the processes being listed).

\begin{tabular}{lccccccc}
\hline Plant & Phase Separation & $\mathrm{RSF}$ & $\mathrm{O}_{3}$ & $\mathrm{RSF}$ & $\mathrm{GAC}$ & $\mathrm{BAC}$ & Total Removal \\
\hline Vaalkop & $5 \%$ & & $5 \%$ & & $8 \%$ & & $29 \%$ \\
Vereeniging & $18 \%$ & $-2 \%$ & & & & & $20 \%$ \\
Balkfontein & $11 \%$ & $6 \%$ & & & & & $29 \%$ \\
Stilfontein & $19 \%$ & & $12 \%$ & $-1 \%$ & & & $37 \%$ \\
Von Bach & $18 \%$ & $15 \%$ & & & & $32 \%$ & $81 \%$ \\
Goreangab & $29 \%$ & $16 \%$ & $9 \%$ & & & $32 \%$ & \\
\hline
\end{tabular}

All abbreviations same as previously defined in Table 2 .

\subsection{Results}

Figure 1 shows the DOC removal at the six WTPs for each unit process. The DOC levels in the raw water are very high $(>10 \mathrm{mg} / \mathrm{l})$ at all the WTPs except Von Bach. Therefore DOC removal is an important operational objective at these WTPs as it is above the prescribed maximum limit of $10 \mathrm{mg} / \mathrm{l}$ in treated water. However, the DOC removal is poor with DOC values mostly greater than the guideline value of $5 \mathrm{mg} / \mathrm{l}$ in the final treated water except at Von Bach and Goreangab where the DOC is reduced to $4.2 \mathrm{mg} / \mathrm{l}$ and $2.0 \mathrm{mg} / \mathrm{l}$ respectively in the treated water.

Table 3 shows the DOC removal for each individual unit process. Enhanced Coagulation (EC), Dissolved Air Floatation (DAF), and Settling Tank (ST) are primarily phase separation methods and have been grouped together in Table 3 for analysis. Evidently, DOC removal is inconsistent for each individual process for different raw water sources hinting at strong differences in the NOM composition between the raw water sources such as molecular weight and bio-availability. This demonstrates that the monitoring of DOC only brings limited insight into process performance and thus is not adequate for design or process optimization. Therefore further DOC characterization is required to reveal the NOM characteristics responsible for these differences.

NOM is a collection of organic molecules with highly versatile chemical and physical structures. Organic compounds found in natural waters can be classified into six major structural groups, namely: humic substances, hydrophilic acids, carboxylic acids, carbohydrates, amino acids, and hydrocarbons. From this composition, we can deduce six properties of NOM relevant to water treatment, namely: (1) humicity, (2) bioavailability, (3) molecular weight distribution, (4) functional groups, (5) hydrophobicity/hydrophilicity, and (6) charge distribution (Mwesigwa, 2007). Tracking these properties of NOM through the treatment train can reveal more information about process performance than the analysis presented in this section.

\section{Fractionation of NOM into biodegradable and non-biodegradable fractions}

This section deals with the bio-available fractionation of the NOM identified above, which classifies NOM based on its ability to support microbial growth. This is important in order to evaluate the biostability of water and disinfection demand in the distribution system and the performance of individual unit processes. Bio-available NOM had been previously quantified as assimilable organic carbon (AOC) and biodegradable dissolved organic carbon (BDOC) (Escobar and Randall, 2000; Liua et al., 2002).

AOC is the part of DOC that can be easily assimilated by bacteria and converted to cell mass and indicates bacterial regrowth potential in the distribution system. AOC is mainly related to NOM with molecular weight less than $1000 \mathrm{Dal}-$ ton. This fraction of NOM with molecular weight less than 1000 Dalton corresponds to $16-38 \%$ of DOC and 4-9\% of the colour (Hem and Efraimsen, 2001). BDOC is a measure of both the DOC that is mineralised and assimilated by bacteria and indicates disinfection demand and disinfection by-product formation potential (DBFP). The quotient AOC/BDOC may be regarded as an indication of the relative biological stability of the biodegradable organic compounds present in drinking water (Van der Kooij, 1990). AOC and BDOC therefore provide complementary information. Based on the above, BDOC should be more suitable as a treatment process control parameter while AOC should be more suitable for distribution system water quality control. Very few studies in South Africa had been done using AOC, but more recently BDOC has been included in studies from Namibia.

\subsection{Experimental}

For the determination of BDOC, an inoculum was added to a fixed mass of sample, aerated and kept at ambient temperature. For the measurements reported in this study, the ambient temperature was $18^{\circ} \mathrm{C}$ during the winter months and $22^{\circ} \mathrm{C}$ in summer. Daily measurements of DOC were taken until no further change in DOC could be observed. This took 5 to 7 days. The BDOC was then calculated as the difference 
Table 4. Tracking NOM at the New Goreangab Water Reclamation Plant (removal expressed as percentages of the raw water concentration).

\begin{tabular}{lcccccc}
\hline Stage & $\begin{array}{c}\text { DOC } \\
(\mathrm{mg} / \mathrm{l})\end{array}$ & $\begin{array}{c}\text { BDOC } \\
(\mathrm{mg} / \mathrm{l})\end{array}$ & $\begin{array}{c}\text { NBDOC } \\
(\mathrm{mg} / \mathrm{l})\end{array}$ & $\begin{array}{c}\text { DOC } \\
(\% \text { Removal })\end{array}$ & $\begin{array}{c}\text { BDOC } \\
(\% \text { Removal })\end{array}$ & $\begin{array}{c}\text { NBDOC } \\
(\% \text { Removal })\end{array}$ \\
\hline Raw water & 10.81 & 3.20 & 7.61 & - & - & - \\
$\mathrm{DAF}$ & 7.66 & 2.77 & 4.88 & 29 & 13 & 36 \\
$\mathrm{RSF}$ & 6.45 & 1.27 & 5.17 & 11 & 47 & 24 \\
$\mathrm{O}_{3}$ & 5.89 & 2.37 & 3.51 & 5 & -34 & -6 \\
BAC & 3.95 & 1.29 & 2.66 & 18 & 34 & 11 \\
Final water & 1.97 & 0 & 1.97 & 18 & 40 & 9 \\
Total Removal (\%) & & & & 82 & 100 & 74 \\
\hline
\end{tabular}

between the initial DOC and the final DOC. This procedure was optimised for inoculum size, incubation period and aeration.

During the study reported here, biologically active antracite was taken from an operational rapid sand filter at a water treatment plant, providing a well adapted heterogeneous culture. The anthracite was pre-washed 10 times with distilled water until no DOC in the distilled water was detected. The initial DOC of the water sample to be tested $\left(\mathrm{DOC}_{\mathrm{o}}\right.$ ) was then determined. A water sample of $300 \mathrm{ml}$ was mixed with $100 \mathrm{~g}$ of antracite and mixed gently. Air flow at a rate of $2-41 / \mathrm{h}$ was bubbled continuously through the water-anthracite mixture at ambient temperature for 5 days. Every $24 \mathrm{~h}$ a $20 \mathrm{ml}$ sample was taken and filtered through a $0.45 \mu \mathrm{m}$ filter to determine the DOC on a Tekmar Dohrman Phoenix 8000 Total Organic Carbon analyser. The difference between the initial $\mathrm{DOC}_{\mathrm{i}}$ and the minimum $\mathrm{DOC}_{\min }$ reached after 5 days was regarded as the BDOC. The difference $\mathrm{DOC}_{\mathrm{i}}-\mathrm{DOC}_{\mathrm{o}}$ must be less than $0.2 \mathrm{mg} / \mathrm{l}$ according to the assay. The $\mathrm{DOC}_{\min }$ was taken as the non-biodegradable dissolved organic carbon fraction (NBDOC).

This sampling and analysis programme formed part of research project at the New Goreangab Water Reclamation Plant (NGWRP) in Windhoek and is documented elsewhere in more detail (Menge et al., 2009).

\subsection{Results}

The New Goreangab Water Reclamation Plant uses a blend of water from a dam and effluent from a wastewater treatment plant as the raw water source in a ratio which varies from 1:20 to $1: 12$. The configuration of the plant consists of pre-ozonation $\left(\mathrm{O}_{3}\right)$, enhanced coagulation (EC), dissolved air flotation (DAF), followed by sand filtration (SF), ozonation $\left(\mathrm{O}_{3}\right)$, and biological activated carbon (BAC). After BAC water passes through granular activated carbon (GAC), ultrafiltration (UF), chlorination (CL), and stabilization (SB) with sodium hydroxide to achieve a calcium carbonate precipitation potential (CCPP) of 2 to $4 \mathrm{mg} / \mathrm{l}$ as calcium carbonate. Grab samples were collected after each treatment step for analysis. Four replicates were collected during each sampling period. Samples were collected during the period from October 2007 to November 2008. Average values for the DOC tracking after various treatment units for one sampling run are shown in Table 4.

The following observations can be made from these results:

1. NBDOC and BDOC are $70 \%$ and $30 \%$ respectively in the raw water. This is consistent with the composition of the raw water, which consists mainly of effluent from a wastewater treatment plant.

2. DAF preferentially removes the NBDOC fraction and is fairly unresponsive to the biodegradable part of the DOC.

3. RSF targets mostly the BDOC fraction. Haarhoff and Van Staden (2006) demonstrated the existence of an active biofilm in rapid sand filters. Biological activity in this biofilm might be responsible for the consumption of the BDOC fraction. This unit process reduces the BDOC fraction to only $20 \%$ of the total DOC.

4. $\mathrm{O}_{3}$ increases the BDOC fraction by $34 \%$. This is consistent with the common understanding that ozone breaks down larger, complex molecules to smaller biodegradable units.

5. BAC reduces the BDOC fraction by $34 \%$, an equal magnitude to the increase in BDOC during ozonation. Therefore $\mathrm{O}_{3}$ and BAC are complimentary processes.

There is $100 \%$ removal of BDOC in the effluent and the remaining $1.97 \mathrm{mg} / \mathrm{l}$ of DOC in the effluent is entirely NBDOC. Baghoth et al. (2008) tracked DOC through the urban water cycle and noted that the biodegradable fraction was readily removed during drinking water treatment whereas the nonbiodegradable fraction would persist throughout the urban water cycle. This is consistent with the observations reported here. 


\section{Fractionation of NOM by liquid size exclusion chromatography (LSEC)}

Liquid size exclusion chromatography (LSEC) is a technique which fractionates NOM based on molecular weight distribution (MWD). Size is an important characteristic in water treatment as diffusion coefficients and removal efficiencies are directly dependent on the size of the solute. NOM exhibits different characteristics depending on its MWD both in terms of treatability and potential water quality problems. The design, integration and performance of processes such as coagulation, dissolved air flotation, solid media and membrane filtration, sorption on granular activated carbon, disinfection and potential re-growth in the distribution system are strongly influenced by the MWD of the NOM (Tadanier et al., 2000).

This sampling and analysis programme formed part of a research project at the Goreangab water treatment plant and is documented elsewhere in more detail (Jacquemet et al., 2007).

\subsection{Experimental}

The LSEC consists of a liquid chromatography column coupled to on-line ultraviolet absorbance (UVA), Fluorescence and DOC detectors. The chromatography column separates NOM molecules based on molecular size so that the largest molecules are eluted first and the smallest molecules are eluted last in the column. This is because molecules that are smaller than the pore size can enter the particles and will thus have longer transit time than larger molecules as the larger molecules can not penetrate the pores very deeply. The elution time can then be plotted against the DOC on one axis, the UVA, and/or the Fluorescence on the other axis. Using the resultant plot, NOM can then be characterised into high or low molecular weight and humic or non-humic fractions. However, it should be noted that other properties of the stationary phase such as surface charge also affect the retention time of the fractions.

Using a calibration based on potassium hydrogenophtalate, the different peaks of the chromatogram were integrated to define and evaluate the proportion of each organic fraction. The chromatographable DOC (CDOC) was measured as the sum of all chromatographic fractions identified; hence this is the hydrophobic part of NOM. The hydrophilic fraction (HDOC) was then determined as the difference between the total DOC and CDOC.

The first fraction was detected after 25-35 min and this comprises the largest molecules attributed to polysaccharides (PS), proteins and colloids. The second peak was observed after $35-50 \mathrm{~min}$ and is attributed to aromatic organic molecules of high molecular weight such as humic substances and the corresponding building blocks (HS + BB). The third fraction, detected after 50-60 min, comprises the
Table 5. Removal rates of the three molecular weight fractions of NOM.

\begin{tabular}{cccc}
\hline Stage & \multicolumn{3}{c}{ Removal Rate $(\%)$} \\
& PS $^{*}$ & HS + BB & A + N \\
\hline DAF & 39 & 24 & 23 \\
SF & 13 & 6 & 15 \\
$\mathrm{O}_{3}$ & 1 & 13 & 9 \\
BAC & -11 & -3 & 2 \\
GAC & 19 & 29 & 33 \\
UF & 19 & -2 & -2 \\
\hline
\end{tabular}

* Considering the small fraction of PS in the raw water $(<5 \%)$, the removal percentages of this fraction shown in the table are not conclusive also because of the accuracy limitations of the equipment.

smallest molecules and is attributed to low molecular weight organic acids and neutrals $(\mathrm{A}+\mathrm{N})$.

\subsection{Results}

The proportions of these fractions in the sewage effluent were: $\mathrm{PS}<5 \%$, $\mathrm{HS}+\mathrm{BB}=60-65 \%$ and $\mathrm{A}+\mathrm{N}=15 \%$. Considering the ratio between dam water and sewage effluent respectively, the blend exhibited a composition similar to the sewage effluent. The removal of the three fractions is shown in Table 5 after each unit process.

The following observations can be made:

1. DAF removes the highest molecular weight fractions better, while the removal of the intermediate and lower molecular weight fractions is comparable.

2. SF targets the highest and lowest molecular weight fractions. Biodegradation in the biofilm is probably responsible for the removal of the lowest molecular weight fractions because they are likely to be highly biodegradable. Lower molecular weight compounds of NOM enhance biodegradability because they are more easily transported across the bacterial cell membrane and attacked by the metabolic enzymes (Leisinger et al., 1981).

3. Ozonation attacks specifically unsaturated bonds, which are frequently present in humic acids, to a lesser extent in low molecular weight organic acids and neutrals and hardly present in polysaccharides. This will lead to the formation of easily degradable small organic acids like acetic or oxalic acid or even complete mineralization. This probably explains the relative magnitudes of the observed decrease of the molecular weight fractions as shown in Table 5. Furthermore, HS can be transformed to BB during ozonation. Therefore when the two fractions are combined information is lost. 
4. The increase in PS during BAC treatment may be possibly explained by the increase in excretion products of the bacteria growing on the media. Alternatively, residual ozone is left in the water after the preceding ozonation step.

5. Results for GAC are consistent with the literature that it targets mostly low to intermediate molecular weight fractions. A portion of the GAC may also be functioning as a BAC.

6. Ultrafiltration is observed to target the high molecular weight fractions. This is probably due to size rejection by the membranes.

\section{Fractionation of NOM by ion exchange resins}

NOM can be characterised into hydrophobic and hydrophilic fractions based on their affinity for water. The hydrophilic fraction has more affinity for water and is composed mainly of low molecular weight carbohydrates, proteins and amino acids. The hydrophobic fraction has less affinity for water thus more soluble in organic solvents and is composed mainly of humic and fulvic acids. The affinity for water by the hydrophilic species is attributed to their charged/polarized molecular structure which enables them to form hydrogen bonds with water thus more readily soluble in water than polar solvents. The hydrophobic species tend to be electrically neutral and non-polar, and thus readily soluble in neutral and non-polar solvents.

The hydrophobic and hydrophilic species can be further partitioned based on their ability to donate or accept a proton into acidic, basic, and neutral sub-groups. The acidic group is comprised mainly of carboxylic acids and phenols and it is the anionic character of this functional group that gives NOM its aqueous solubility, high affinity for metal complexation, and buffer capacity. The basic group is composed of amines and amides and is found in amino acids, poly peptides and aquatic humic substances. Because they are basic, they are readily adsorbed by sediments (Thurman and Malcolm, 1981). The most important neutral functional groups of NOM are hydroxyl, ether, ketone, aldehyde, ester and lactone. These functional groups are present in aquatic humic substances, carbohydrates, tannins, and ketoacids and because they contain oxygen, they are able to form bonds with water molecules when they dissolve.

\subsection{Experimental}

Ion exchange resins at pre-adjusted $\mathrm{pH}$ values were used to fractionate the NOM. Amberlite XAD resins were used to isolate the hydrophobic fractions of NOM. Dianion WA-10 and Dowex 88 resins were used after the XAD resins to isolate the hydrophilic fractions. This procedure was done at pre-adjusted $\mathrm{pH}$ using appropriate solvents to elute the adsorbed fractions. Six NOM fractions were obtained, namely:

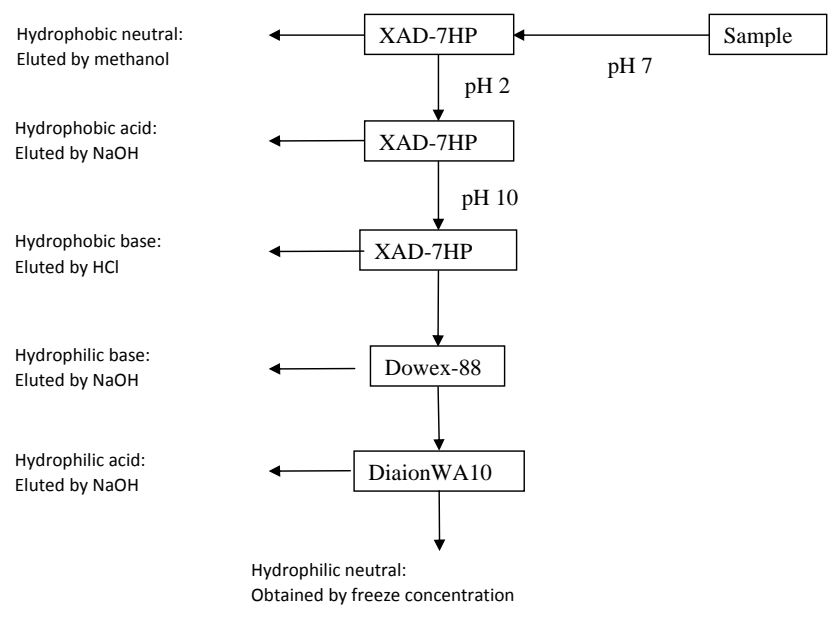

Figure 2. Steps applied during NOM fractionation using ion exchange resins.

hydrophobic acids (HpoA), hydrophobic bases (HpoB), hydrophobic neutrals (HpoN), hydrophilic acids (HpiA), hydrophilic bases (HpiB) and hydrophilic neutrals (HpiN).

This technique was used to investigate the treatability of NOM by ozonation at Vaalkop WTP. Ozone is a highly reactive oxidant. Ozone specifically targets unsaturated bonds which results in a shift in molecular weight and a consequent increase in low molecular weight fractions (Goel et al., 1995) which are often biodegradable (Ciardelli et al., 2001).

Two litre samples were collected before and after ozonation and analysed for the six fractions. The methodology of this fractionation technique is illustrated in Fig. 2. This sampling and analysis programme formed part of a postgraduate project at the Department of Chemical Technology at the University of Johannesburg and is fully documented elsewhere (Nkambule, 2009).

\subsection{Results}

Table 6 shows the composition of the water before ozonation. Other studies have shown that the hydrophilic fraction is more abundant in natural water (between 55-70\%) than the hydrophobic fraction while the basic fraction only constitutes 2-3\% (Thurman, 1985). Therefore these water samples before ozonation do not conform to the observations of earlier researchers probably because of the effects of unit processes preceding the ozonation.

Figure 3 shows the removal of the six NOM fractions at Vaalkop WTP by ozonation during four sampling periods.

Fractionation of NOM after ozonation based on hydrophobicity and hydrophilicity reveals that ozonation removes mostly the hydrophilic fraction. A parallel fractionation into basic, acidic and neutral fractions shows that the basic fraction is more amenable to removal by ozonation whereas the acidic and neutral fractions increase marginally. Coupling of 
Table 6. Composition of the water before ozonation in $\mathrm{mg} / \mathrm{l}$.

\begin{tabular}{lccccccccccc}
\hline Sampling Date & Hpo & Hpi & B & A & N & HpoB & HpoA & HpoN & HpiB & HpiA & HpiN \\
\hline Dec 2007 & 5.4 & 4.9 & 4.5 & 3.2 & 2.6 & 1.3 & 2.3 & 1.8 & 3.2 & 0.9 & 0.8 \\
Jan 2008 & 5.7 & 5.6 & 4.6 & 3.5 & 3.2 & 1.5 & 2.5 & 1.7 & 3.1 & 1.0 & 1.5 \\
Feb 2008 & 6.6 & 6.5 & 5.5 & 3.7 & 3.9 & 1.4 & 3.0 & 2.2 & 4.1 & 0.7 & 1.7 \\
Mar 2008 & 3.3 & 2.8 & 2.3 & 2.7 & 1.1 & 0.8 & 1.8 & 0.7 & 1.5 & 0.9 & 0.4 \\
\hline
\end{tabular}

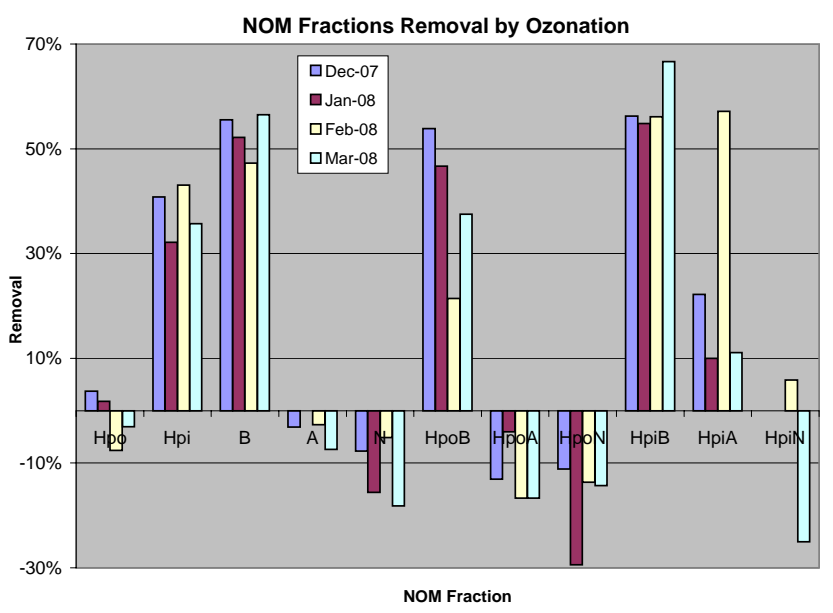

Figure 3. Removal of different NOM fractions by ozonation at Vaalkop WTP.

these properties reveals that the $\mathrm{HpoB}, \mathrm{HpiB}$, and HpiA are removed while there is an increase in the HpoA and HpoN fractions. The impact on the HpiN fraction was inconsistent. Furthermore, the magnitude of the changes in these fractions due to ozonation varied significantly during the sampling period which may point to problems with reproducibility which require further investigation.

\section{Summary and conclusions}

The operational mechanisms of most unit processes are well understood. However, their interaction with NOM is not well understood. Water treatment process designers would ultimately like to have a firm, rational footing for selecting processes for NOM removal. In its most ideal form, one would determine the different NOM components in a raw water source, and then select those processes that will reduce the most dominant NOM components. In this respect, the results of the research projects reported earlier are encouraging. It was possible to show that the NOM fractions responded very differently to different unit processes. Furthermore, the observed impact of some unit processes relies heavily on the technique for NOM characterisation.
NOM was tracked at six WTPs using DOC measurements. Fractionation of the DOC based on biodegradability and molecular weight distribution was done at a WTP in Namibia. A third fractionation technique based on the hydrophilic/hydrophobic characteristics of NOM was used to assess the impact of ozonation on DOC.

DOC measurements alone did not give much insight into NOM evolution through the treatment train. The performance of individual processes appeared inconsistent when the raw water source was varied hinting at a strong influence of other important constituents of the NOM. Fractionation of NOM based on biodegradability was more descriptive as the transformation of the BDOC and NBDOC fractions could be related to the operational mechanisms of the individual unit processes. This technique was especially informative for ozonation, rapid sand filtration and biological activated carbon. BDOC fractionation may thus be the analytical technique of choice when oxidation and biofiltration processes have to be analysed more deeply.

The results reported in this paper on molecular weight fractionation showed that rapid sand filtration targets the low and high molecular weight fractions, GAC targets the low to intermediate molecular weight fractions, and UF targets the high molecular weight fraction. These results are consistent with the operational mechanisms of these unit processes and thus can be used for operational analysis and/or optimization of these processes.

Fractionation using ion exchange resins showed wide variations during different sampling runs, which may point to problems with reproducibility. The technique, however imperfect it may be at present, did show up large differences in the NOM response to ozonation, which may turn out to be a potentially powerful tool for better understanding of NOM transformation and removal.

Taken together, there can be no argument that NOM fractionation, beyond the usual DOC analysis, is an important prerequisite for better understanding NOM, and designing of water treatment plants for its optimal removal. The results presented in this paper, gleaned from studies by different parties, clearly demonstrated the high variability of NOM at the Southern African Water Treatment Plants which treat typical surface water, and the very different responses of different NOM fractions to different unit processes. 
Acknowledgements. The researchers at the University of Johannesburg appreciate the funding from the National Research Foundation of South Africa, and ESKOM's Tertiary Support Program (TESP). The City of Windhoek appreciates the support it received from WINGOC, Veolia and University of Namibia during the NOM characterisation project executed from 2005 to 2007.

Edited by: B. Heijman

\section{References}

Amy, G., Kuo, C. J., and Sierka, R.: Ozonation of humic substances: Effects on molecular weight distributions of dissolved organic carbon and trihalomethane formation potential, OzoneSci. Eng., 10, 39-49, 1988.

Arruda, J. A. and Fromm, C. H.: Relationships among trihalomethane formation potential, organic carbon and lake enrichment, Environ. Pollut., 61, 199-209, 1989.

Baghoth, S. A., Maeng, S. K., Rodriguez, S. G. S., Ronteltap, M., Sharma, S., Kennedy, M., and Amy, G. L.: An urban water cycle perspective of natural organic matter (NOM)-NOM in drinking water, wastewater effluent, stormwater and seawater Natural Organic Matter: From Source to Tap Conference, Bath, UK, 2008.

Chen, C., Zhang, X., He, W., Lu, W., and Han, H.: Comparison of seven kinds of drinking water treatment processes to enhance organic material removal: A pilot test, Sci. Total Environ., 93$102,2007$.

Ciardelli, J. E., Capannelli, G., and Bottino, A.: Ozone treatment of textile wastewaters for reuse, Water Sci. Technol., 44, 61-67, 2001.

Edzwald, J. K. and Tobiason, J. E.: Enhanced coagulation: US requirements and a broad view, Water Sci. Technol., 40, 63-70, 1999.

Escobar, I. C. and Randall, A. A.: Sample storage on the assimilable organic carbon (AOC) bioassay, Water Res., 34, 1680-1686, 2000.

Goel, S., Hozalski, R. M., and Bouwer, E. J.: Biodegradation of NOM: effect of NOM source and ozone dose, J. Am. Water Works Ass., 87, 90-105, 1995.

Gunten, U. V., Driedger, A., Gallard, H., and Salhi, E.: By-products formation during drinking water disinfection: A tool to assess disinfection efficiency?, Water Res., 35, 2095-2099, 2001.

Haarhoff, J. and Van Staden, S. J.: Measuring the cleanliness of filter media, Ninth Biennial WISA Conference, Durban International Conference Centre, 2006.

Hem, L. J. and Efraimsen, H.: Assimilable organic carbon in molecular weight fractions of natural organic matter, Water Res., 35, 1106-1110, 2001.

Jacquemet, V., Gherman, E. C., Konig, E., and Theron-Beukes, T.: Organic Matter Evolution In The Treatment Process Of The New Goreangab Water Reclamation Plant At Windhoek, Namibia, 6th International Water Association (IWA) Specialist Conference on Wastewater Reclamation and Reuse for Sustainability - Guiding the Growth of Water Reuse, Antwerp, Belgium, 2007.
Lee, N., Amy, G., Habarou, H., and Schrotter, J. C.: Identification and control of fouling of low-pressure (MF and UF) membranes by drinking-water natural organic matter, Water science and technology: Water supply, 3, 217-222, 2003.

Lehtola, M. J., Miettinen, I. T., Vartiainen, T., Myllkangas, T., and Martikainen, P.: Microbially available organic carbon, phosphorus, and microbial growth in ozonated drinking water, Water Res., 35, 1635-1640, 2001.

Liua, W., Wua, H., Wanga, Z., Ongb, S. L., Hub, J. Y., and Ngb, W. J.: Investigation of assimilable organic carbon (AOC) and bacterial regrowth in drinking water distribution system, Water Res., 36, 891-898, 2002.

Matsebula, B.: Evaluation of Water Treatment Processes In The Removal of Natural Organic Matter And Disinfection By-Products Using Cyclodextrin Polymers, MSc, Chemical Technology, University of Johannesburg, Johannesburg, 2009.

Menge, J., Nikodemus, K., and Namundjanga, J.: A Simplified Method To Determine Biodegradable Organic Carbon (BDOC) In Drinking Water, 2nd Drinking Water Quality Conference, Port Elizabeth, South Africa, 2009.

Mwesigwa, J. K.: Relating NOM characteristics to treatability of groundwater: A case study of Vitens water supply company water treatment plants, MSs, Municipal Water and Infrastructure, UNESCO-IHE Institute for Water Education, Delft, 108 pp., 2007.

Nkambule, T.: Removal of Natural Organic Matter Using Ion Exchange Chromatography and Cyclodextrin Polyurethanes, MSc, Chemical Technology, University of Johannesburg, Johannesburg, 2009.

Olivieri, V. P., Bakalian, A. E., Bossung, K. W., and Lowther, E. D.: Recurrent coliforms in water distribution systems in the presence of free residual chlorine, in: Water chlorination, chemistry, environmental impacts and health effects, edited by: Jolley, R. L., Bull, R. J., Davis, W. P., Katz, W., Roberts, M. H., and Jacobs, V. A., Lewis Publishers Inc., Chelsea, MI, USA, 1984.

Swartz, C. D., Morrison, I. R., Thebe, T., Engelbrecht, W. J., Cloete, V. B., Knott, M., Loewenthal, R. E., and Kruger, P.: Characterisation and chemical removal of organic matter in South African coloured surface waters, Water Research Comission, Report No. 924/1/03, 2004.

Tadanier, C. R., Berry, D., and Knocke, W. R.: Dissolved Organic Matter Apparent Molecular Weight Distribution and NumberAverage Apparent Molecular Weight by Batch Ultrafiltration, Environ. Sci. Technol., 34, 2348-2353, 2000.

Thurman, E. M. and Malcolm, R. L.: Preparative isolation of aquatic humic substances, Environ. Sci. Technol., 15, 463-466, 1981.

Van der Kooij, D.: Assimilable organic carbon in drinking waters, in: Drinking water microbiology, edited by: Mcfeters, G. A., New York, 57-87, 1990.

Westerhoff, P., Chaob, P., and Mash, H.: Reactivity of natural organic matter with aqueous chlorine and bromine, Water Res., 38, 1502-1513, 2004. 